\title{
Hypermethylation of genomic 3.3-kb repeats is frequent event in HPV-positive cervical cancer
}

\author{
Alexey N Katargin, Larissa S Pavlova, Fjodor L Kisseljov and \\ Natalia P Kisseljova*
}

\begin{abstract}
Address: Laboratory of Molecular Biology of Viruses, Institute of Carcinogenesis, NN Blokhin Cancer Research Center, Russian Academy of Medical Sciences, Moscow, Russia

Email: Alexey N Katargin - akatar@yandex.ru; Larissa S Pavlova - Lar9115@yandex.ru; Fjodor L Kisseljov - f_kiss@crc.umos.ru; Natalia P Kisseljova* - natalia-kis@yandex.ru

* Corresponding author
\end{abstract}

Published: 27 May 2009

BMC Medical Genomics 2009, 2:30 doi:10.1 186/1755-8794-2-30

This article is available from: http://www.biomedcentral.com//755-8794/2/30

(c) 2009 Katargin et al; licensee BioMed Central Ltd.

This is an Open Access article distributed under the terms of the Creative Commons Attribution License (http://creativecommons.org/licenses/by/2.0), which permits unrestricted use, distribution, and reproduction in any medium, provided the original work is properly cited.
Received: 18 December 2008

Accepted: 27 May 2009

\begin{abstract}
Background: Large-scale screening methods are widely used to reveal cancer-specific DNA methylation markers. We previously identified non-satellite $3.3-\mathrm{kb}$ repeats associated with facioscapulohumeral muscular dystrophy (FSHD) as hypermethylated in cervical cancer in genomewide screening. To determine whether hypermethylation of 3.3-kb repeats is a tumor-specific event and to evaluate frequency of this event in tumors, we investigated the 3.3-kb repeat methylation status in human papilloma virus (HPV)-positive cervical tumors, cancer cell lines, and normal cervical tissues. Open reading frames encoding DUX family proteins are contained within some 3.3-kb repeat units. The DUX mRNA expression profile was also studied in these tissues.
\end{abstract}

Methods: The methylation status of 3.3-kb repeats was evaluated by Southern blot hybridization and bisulfite genomic sequencing. The expression of DUX mRNA was analyzed by RT-PCR and specificity of PCR products was confirmed by sequencing analysis.

Results: Hypermethylation of 3.3-kb repeats relative to normal tissues was revealed for the first time in more than $50 \%$ (18/34) of cervical tumors and in 4 HPV-positive cervical cancer cell lines. Hypermethylation of 3.3-kb repeats was observed in tumors concurrently with or independently of hypomethylation of classical satellite 2 sequences (Sat2) that were hypomethylated in 75\% (I5/ 20) of cervical tumors. We have revealed the presence of transcripts highly homologous to DUX4 and DUX 10 genes in normal tissues and down-regulation of transcripts in $68 \%$ of tumors with and without 3.3-kb repeats hypermethylation.

Conclusion: Our results demonstrate that hypermethylation rather than hypomethylation of 3.3$\mathrm{kb}$ repeats is the predominant event in HPV-associated cervical cancer and provide new insight into the epigenetic changes of repetitive DNA elements in carcinogenesis.

\section{Background}

DNA methylation plays an important role in the maintenance of the gene expression program and genome stability. Tumor cells are characterized by a paradoxical change in DNA methylation pattern: global DNA demethylation and local hypo- and hypermethylation of gene regulatory regions that result in transcriptional activation of oncogenes and inactivation of tumor suppressors. Current 
opinion is that the targets for aberrant demethylation in tumors are represented by DNA sequences that are methylated in normal tissues. Repetitive elements are considered among such DNA sequences. Frequent hypomethylation of repetitive elements is observed in diverse human cancers and is thought to largely account for genomic instability [1-3].

Cervical carcinomas are the second most frequent type of cancer in women. Infection with high risk type human papilloma viruses (HR-HPV) is the main risk factor for cervical cancer [4]. HR-HPV infections are extremely widespread throughout the world, but malignant transformation is a rare consequence of the infection. The progression from precursor intraepithelial lesions to cervical carcinomas is accompanied by additional genetic and epigenetic changes that have not been fully characterized. A low overall m5C content compared to normal cervical tissue was demonstrated in cervical cancer, although the methylation status has not been studied in any repetitive elements except LINE-1 $[5,6]$.

We previously conducted a genome-wide differential analysis of DNA methylation in cervical cancer and normal tissues using methylation-sensitive arbitrarily primed PCR [7] and identified CpG islands located within 3.3-kb repeats as hypermethylated in tumors.

Members of the 3.3-kb repeat family reside in the subtelomeric regions of chromosomes 4 and 10 as tandemly arranged polymorphic arrays containing from 11 to 100 monomers. In addition, they are present on the short arms of all acrocentric chromosomes as interspersed repeats [8-11]. The subtelomeric region $4 \mathrm{q} 35$ named D4Z4 receives more attention because of its association with facioscapulohumeral muscular dystrophy (FSHD), an autosomal dominant disorder linked to partial deletion of the D4Z4 repeat array. At least one sequenced copy of $\mathrm{D} 4 \mathrm{Z} 4$ contains a single-exon open reading frame (ORF) and an upstream region that can function as a promoter in reporter assays [12]. The ORF encodes a polypeptide called DUX4 that has a high level of similarity to the paired-type homeodomain proteins of families Pax and Otx [13]. DUX4 and DUX4-related transcripts (DUX1, -3, $-4 c-5$, and -10) have been revealed in some human cells [14-18]. DUX1 and DUX4 have the properties of a transcription factor, and the products of exogenous translation of mRNAs of these genes localize to the cell nucleus $[12,15,19]$.

In many normal somatic tissues $3.3-\mathrm{kb}$ repeats are mostly but not completely methylated, and they are hypomethylated in glioblastomas, leukemia cell lines, tissues of patients with FSHD and with DNA methyltransferase deficiency syndrome ICF [20-24]. It has recently been shown that $3.3-\mathrm{kb}$ repeats in the $\mathrm{D} 4 \mathrm{Z} 4$ array are hypomethylated in some ovarian and Wilms tumors and are hypermethylated in other tumors of the same types relative to normal tissues [25].

To determine whether hypermethylation of 3.3-kb repeats is an event specific for HPV-positive cervical tumors and to evaluate the frequency of this event, we examined the methylation status of $3.3-\mathrm{kb}$ repeats in tumors, cervical cancer cell lines, and normal tissues. We have demonstrated for the first time that more than $50 \%$ of cervical cancers display hypermethylation of $3.3-\mathrm{kb}$ repeats compared to normal cervical tissues. Different regions within the 3.3-kb monomer exhibit inter-individual variation in the methylation patterns in normal tissues and different susceptibility to hypermethylation in tumors. We have shown that the 3.3-kb repeat hypermethylation can occur in tumors concurrently with hypomethylation of classical satellite 2 (Sat2) sequences that, according to many studies, are targets for demethylation in different tumor types [1-3]. We also revealed the presence of transcripts highly homologous to the DUX4 and 10 genes in normal uterine cervical tissues and down-regulation of DUX-related transcripts in tumors with and without the $3.3-\mathrm{kb}$ repeat hypermethylation.

\section{Methods \\ Tissue samples}

Squamous cell carcinomas and adenocarcinomas of uterine cervix and samples of adjacent normal tissues were obtained from patients with FIGO stages I, II, and III of the disease at the Blokhin Cancer Research Center. All tumors were HPV16/18-positive, and E7 viral genes were expressed in all of them according to PCR analysis [26]. Normal tissues of uterine cervix were obtained from patients with uterine polyps or tumors. All tissues were collected under the approval of the Institutional Review Board of the Blokhin Cancer Research Center. Informed consent was obtained from all patients. The study was done in accordance with the principles outlined in the Declaration of Helsinki.

\section{Cell lines}

The HPV-positive human cervical carcinoma cells HeLa, SiHa, CaSki, and C4-I and the HPV-negative C-33A cell line (American Type Culture Collection, USA) were maintained in DMEM supplemented with 10\% FCS. Cells were seeded at standard densities and treated with DNA methyltransferase inhibitor 5-aza-2'-deoxycytidine (5-aza-dC; Sigma, USA) for 3-4 days. The medium containing $5 \mu \mathrm{M}$ 5-aza-dC was changed daily.

\section{DNA and RNA extraction}

DNAs and RNAs were isolated from frozen tissues or cells by homogenization in $4.5 \mathrm{M}$ guanidine isothiocyanate and centrifugation through a cesium chloride cushion as described previously [27]. 


\section{Bisulfite-based cytosine methylation analysis}

The bisulfite conversion reaction was carried out using an EZ DNA Methylation Kit (Zymo Research, USA) according to the manufacturer's instructions under the following conditions: 15 cycles $\left(30 \mathrm{~s}\right.$ at $95^{\circ} \mathrm{C}$ and $15 \mathrm{~min}$ at $50^{\circ} \mathrm{C}$ ). The DNA samples were used for the PCR amplification by JumpStart RedTaq DNA polymerase according to the manufacturer's instructions (Sigma, USA). Three sets of 3.3-kb repeat-specific primers corresponding to three regions on the upper strand of bisulfite-modified DNA were used: (1) Sq-1, sense GAA GGT AGG GAG GAA AAG (pos. 566) and antisense ACT CAA CCT AAA AAT ATA CAA TCT (pos. 796); (2) Sq-2, sense TAT GAA GGG GTG GAG TTT G (pos. 1619) and antisense AAA TAC CAA TAA CCT AAA CCA AC (pos. 1955); (3) Sq-3, sense AGT TTG GAG TTT TTG TAGTAG G (pos. 2942) and antisense CAA AAA TCC CAA ACC AAT CAA CC (pos. 3192) [23]. Hereafter the positions of primers are given according to the $3.3-\mathrm{kb}$ monomer sequence [GenBank: AF 117 653]. The PCR products were cloned into pGEM-T Easy vector (Promega, USA) and used for automated sequencing (ABI Prism 3100-Avant Genetic Analyzer, Applied Biosystems, USA).

\section{Southern blot analysis}

DNA samples $(10 \mu \mathrm{g})$ were digested overnight with methylation-sensitive restriction endonucleases (Fermentas, Lithuania), separated in 1\% agarose gel, transferred to a nylon membrane (Zeta-Probe, Bio-Rad, USA), and hybridized with [ $\left.{ }^{32} \mathrm{P}\right]$-labeled PCR DNA probes for 3.3-kb repeat or Sat2-specific oligonucleotide TCG AGT CCA TTC GAT GAT [28]. Hybridization was performed in 7\% (w/v) SDS (Sigma), $0.5 \mathrm{M}$ sodium phosphate (pH 7.2), and $10 \mathrm{mM}$ EDTA at $65^{\circ} \mathrm{C}$ for the PCR probes or at $42^{\circ} \mathrm{C}$ for the Sat 2 oligonucleotide. Some membranes were rehybridized with the Sat 2 oligonucleotide in $50 \%$ formamide at $42{ }^{\circ} \mathrm{C}$. The membranes were washed 2 or 3 times in $2 \times \mathrm{SSPE} / 0.1 \%$ SDS and in $0.1 \times \mathrm{SSPE} / 1 \%$ SDS at 55 and $42^{\circ} \mathrm{C}$ for the PCR and Sat 2 probes, respectively, and exposed to X-ray film at $70^{\circ} \mathrm{C}$. Intensities of hybridizing signals were determined for paired normal and tumor samples or for each cell line and three samples of healthy cervical tissues from patients with non-cervical pathology in the same blot using the Image-J 1.36b NIH software. The approximate extent of hyper- or hypomethylation was calculated in that way: the ratio of the high-molecular-weight hybridizing signal ( $>4.4$ $\mathrm{kb})$ to the total hybridization signal for each tumor $(\mathrm{T})$ was divided by the analogous ratio for matching normal tissue $(\mathrm{N})$. To calculate $\mathrm{T} / \mathrm{N}$ for cell lines, the average from $\mathrm{N}$ for three healthy cervical tissue samples was used.

\section{Reverse transcription PCR}

RT-PCR was carried with total cellular RNA treated with DNase I (Invitrogen, USA) using reverse transcriptase (Superscript II RNase $\mathrm{H}^{-}$, Invitrogen) according to the manufacturer's instructions. DNA contamination was controlled by conducting the same reaction without reverse transcriptase for each RNA sample. PCR was performed with the DUX4-specific primers (sense CCA CGG AGA CTC GTT TGG AC, pos. 1863, and antisense CCT GGA AAG CGA TCC TTC TCA, pos. 2141) under the following conditions: $94^{\circ} \mathrm{C}$ for $5 \mathrm{~min}$; 35 cycles $\left(94^{\circ} \mathrm{C}, 30 \mathrm{~s}\right.$; $64^{\circ} \mathrm{C}, 30 \mathrm{~s} ; 72^{\circ} \mathrm{C}, 40 \mathrm{~s}$ ), and at $72^{\circ} \mathrm{C}$ for $5 \mathrm{~min}$. To control the content of the initial total mRNA, PCRs were carried out with the primers for GAPDH (sense ACC ACA GTC CAT GCC ATC AC, antisense TCC ACC ACC CTG TTG CTG TA) under the following conditions: $94^{\circ} \mathrm{C}, 5 \mathrm{~min}, 26$ cycles $\left(94^{\circ} \mathrm{C}, 30 \mathrm{~s} ; 58^{\circ} \mathrm{C}, 30 \mathrm{~s} ; 72^{\circ} \mathrm{C}, 1 \mathrm{~min}\right.$, ) and $72^{\circ} \mathrm{C}$ for $5 \mathrm{~min}$. After agarose gel electrophoresis, the PCR products were visualized under ultraviolet light or transferred to a membrane (Hybond-N+, Amersham Biosciences) and probed with DUX4-specific [ $\left.{ }^{32} \mathrm{P}\right]$-labeled internal oligonucleotide TTG GTT TCA GAA TGA GAG GTC ACG (pos. 1996). Intensities of all bands were determined using the Image-J 1.36b NIH software. DUX-specific signals were normalized to GAPDH-specific signals in each sample, and the ratios $\mathrm{N} / \mathrm{T}$ were calculated. The average from five healthy cervical tissue samples was used for unpaired tumor samples. Threefold change in tumors relative to normal tissues was taken into account.

\section{Statistical analysis}

Nonparametric Wilcoxon matched pairs test was used to evaluate the methylation level differences between tumors and adjacent normal tissues. Fisher's exact test (two tailed) and $\chi$-square test were used to compare frequencies of hypermethylation in tumors and normal tissues and portions of methylated $\mathrm{CpG}$ sites in different 3.3-kb monomer regions, respectively. Differences were considered statistically significant when P-values were below 0.05. All statistical procedures were performed using STATISTICA 6 software (StatSoft).

\section{Results \\ Methylation pattern of 3.3-kb repeats in normal cervical tissues by bisulfite genomic sequencing}

First, the 3.3-kb repeat methylation pattern was evaluated in normal cervical tissues, which has not been reported previously. Three regions within the $3.3-\mathrm{kb}$ monomer were selected for bisulfite genomic sequencing (Figure 1): the 5 ' region $(\mathrm{Sq}-1)$; the middle region $(\mathrm{Sq}-2)$ around the DUX-4 transcriptional start site that was described for a single copy cloned from the 4q35 D4Z4 array of an FSHD patient [12]; and the 3 ' region (Sq-3), which was shown to be hypomethylated in glioblastomas [24]. Bisulfite sequencing analysis can detect all closely homologous 3.3-kb copies from D4Z4 and other loci of the genome. Normal cervical tissues from two non-cervical cancer patients (Nc-1 and Nc-2) and two normal tissues adjacent to cervical tumors (15-N and 5-N) were used (Figure 2). The examined regions were unequally methylated in all normal cervical tissues. The levels of methylation varied from $23-61 \%$ for Sq-1 to $55-72 \%$ for Sq-2 and $49-59 \%$ 


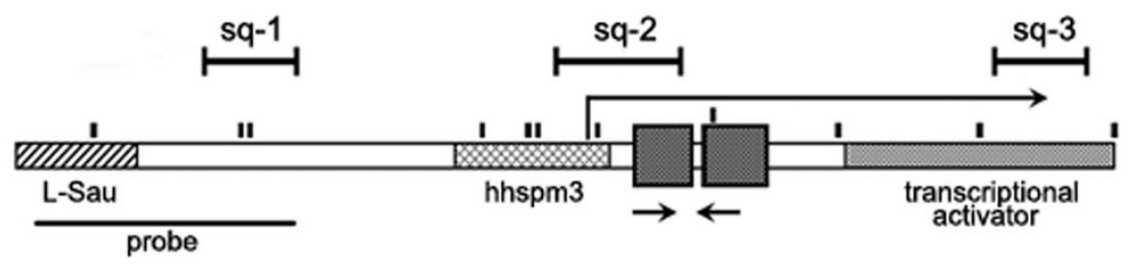

Figure I

Diagram of a 3.3-kb monomer. Two squares denote double homeobox region. Sq-I, Sq-2, and Sq-3 mark the regions selected for sequencing analysis. The hybridization probes and RT-PCR primers are indicated by horizontal lines and arrows, respectively. The broken arrow indicates the position of DUX4 transcription start site. Vertical lines indicate Nael sites.

for Sq-3. In three normal tissues, the Sq-1 regions were significantly less methylated compared to the Sq-2 or Sq-3 regions $\left(\mathrm{P} \leq 10^{-4}\right)$. In addition, significant interindividual variations in the $3.3-\mathrm{kb}$ repeat methylation patterns were revealed. Normal tissues could differ from one another in the local methylation level ( $\mathrm{Nc}-1, \mathrm{Nc}-2,5-\mathrm{N}$ and $15-\mathrm{N}$, Sq1 regions, $\mathrm{P} \leq 0.008$; $\mathrm{Nc}-1$ from $5-\mathrm{N}$ and $15-\mathrm{N}$, Sq-2 regions, $\mathrm{P}<10^{-3}$ ). Finally, these results demonstrated that normal cervical tissues exhibited a considerable but incomplete methylation of 3.3-kb repeats just as shown previously for the 4q35 D4Z4 locus in other normal tissues by Southern blot analysis [21].

\section{Methylation status of 3.3-kb repeats in cervical tumors and cancer cell lines by bisulfite genomic sequencing}

The changes in the 3.3-kb repeat methylation status in tumors were evaluated relative to paired normal tissues taking into account considerable interindividual variation in the repeat methylation pattern. Sequencing analysis demonstrated hypermethylation in two tumors relative to adjacent normal tissues (Figure 2, 5-T and 15-T). It is of interest that the levels of hypermethylation differed among the three regions. The methylation levels of the middle regions $\mathrm{Sq}-2$ did not change substantially in either tumor compared to adjacent tissues $(\mathrm{P}>0.05)$. The Sq-3 regions exhibited moderate but statistically significant levels of hypermethylation in both tumors $(P \leq 0.006)$. At the same time, a more strong increase in the Sq-1 region methylation levels (1.6 and 2 times) was seen in two tumors compared to matched normal tissues $\left(\mathrm{P} \leq 3 \times 10^{-}\right.$ $\left.{ }^{4}\right)$. The strongest level of hypermethylation $(87 \%)$ was revealed in the Sq-1 region in HPV-positive cervical cancer cell line SiHa. Surprisingly, all three regions exhibited hypomethylation in HPV-negative cervical cancer cell line C-33A compared to all other samples examined. The local susceptibility to demethylation also varied $(17 \%, 43 \%$, and $23 \%$ of methylated CpG sites for Sq-1, Sq-2, and Sq3 regions, respectively). These findings demonstrate that the Sq-1 region is more susceptible to changes in the methylation status than other regions and suggest that the changes in methylation status of 3.3-kb repeats in cancer cells may be sequence-specific.

\section{Frequency of hypermethylation of 3.3-kb repeats in cervical HPV-positive carcinomas}

The frequency of hyper- or hypomethylation of 3.3-kb repeats in cervical HPV-positive carcinomas was studied by Southern blot analysis of 34 paired samples using the fragment of the 5' end of the 3.3-kb monomer as a hybridization probe and NaeI methylation-sensitive restriction endonuclease (Figure 3). Eleven $\underline{\mathrm{Na} I}$ sites reside within the 3.3-kb monomer including two sites located within the Sq1 region (Figure 1). This analysis shows the overall methylation status of all copies of the repeats. The methylation levels in tumors were compared to those in nonmalignant cervical tissues of the same patient taking into account individual variations of methylation patterns of $3.3-\mathrm{kb}$ repeats. Indeed, the percentage of undigested DNA (high-molecular-weight fragments $>4.4 \mathrm{~kb}$ ) of normal tissues from different individuals substantially varied, confirming interindividual distinctions in the 3.3-kb repeat methylation level revealed by sequencing analysis (Figure 3A, 44 to $66 \%$ in the same blot). Hypermethylation of $3.3-\mathrm{kb}$ repeats was revealed in 18 out of $34(53 \%)$ carcinomas compared to adjacent normal tissues (Figure $3 \mathrm{C} ; \mathrm{P}=10^{-4}$ ). The samples with low (15-T) and middle (5-T) levels of hypermethylation determined by Southern blot exhibited clearly detectible hypermethylation status by bisulfite genomic sequencing (Figure 2). The hypermethylation of $3.3-\mathrm{kb}$ repeats was shown also in HPV-positive line SiHa by both Southern blot and sequencing analysis, and both techniques demonstrated the 3.3-kb repeat hypomethylation in HPV-negative cell line C-33A. Thus, the results of both techniques coincide with each other and sequencing data verify the sensitivity of Southern blot for detecting differences in DNA methylation. None of the $34 \mathrm{HPV}$-positive tumors displayed such low methylation level as HPV-negative cell line C-33A did (Figure 3A and 3C). No correlation was found between the 3.3-kb repeat methylation status and clinicopathological data (age, tumor stage, and histological grade and type). This indicates that the 3.3-kb repeat hypermethylation may be an early event during cervical carcinogenesis. Thus, these results demonstrate that hypermethylation rather than hypomethylation of $3.3-\mathrm{kb}$ repeats is a frequent event in HPV-positive cervical carcinomas. 
Sq-1

Sq-2

Sq-3

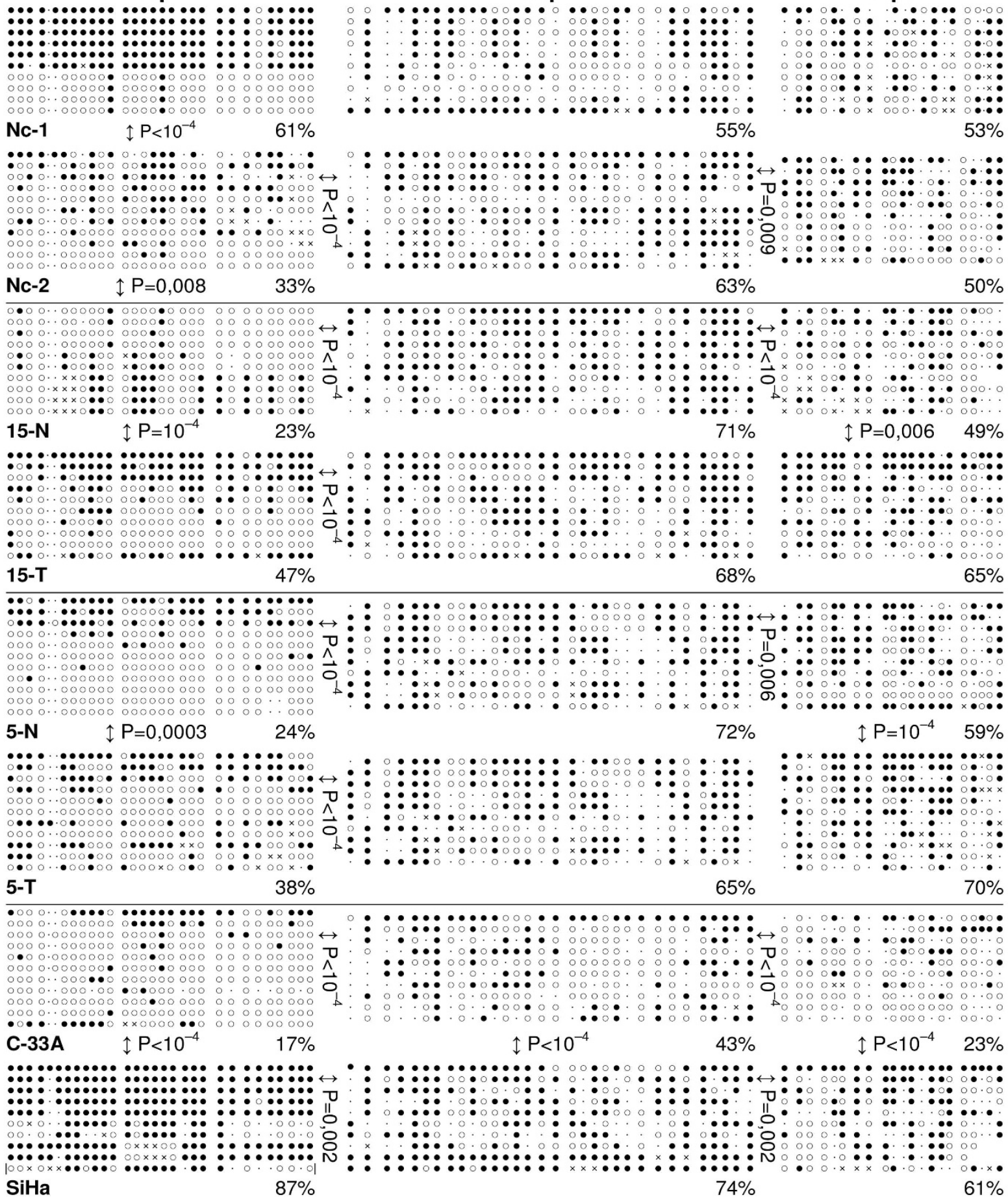

Figure 2

Methylation status of $\mathbf{3 . 3 - k b}$ repeats by sodium bisulfite sequencing in cervical tissues, tumors, and cell lines. Sq-I, Sq-2, and Sq-3 mark three regions of 3.3-kb monomer selected for sequencing. Each row of circles represents a cloned DNA molecule; closed circle, methylated CpG; open circle, unmethylated CpG; dot, CpG site lost from the consensus sequence due to mutations; cross, CpG site status was not determined. The percentage of methylated $C_{p G s}$ among all $C_{p G s}$ analyzed is given below each sample. Nc, normal cervix from non-cervical-cancer patients; T, tumor; N, tumor - tumor-adjacent normal tissue. Numbers of patients are indicated as in Figure 3C. Only P values below 0.05 are given ( $\chi$-square test). 


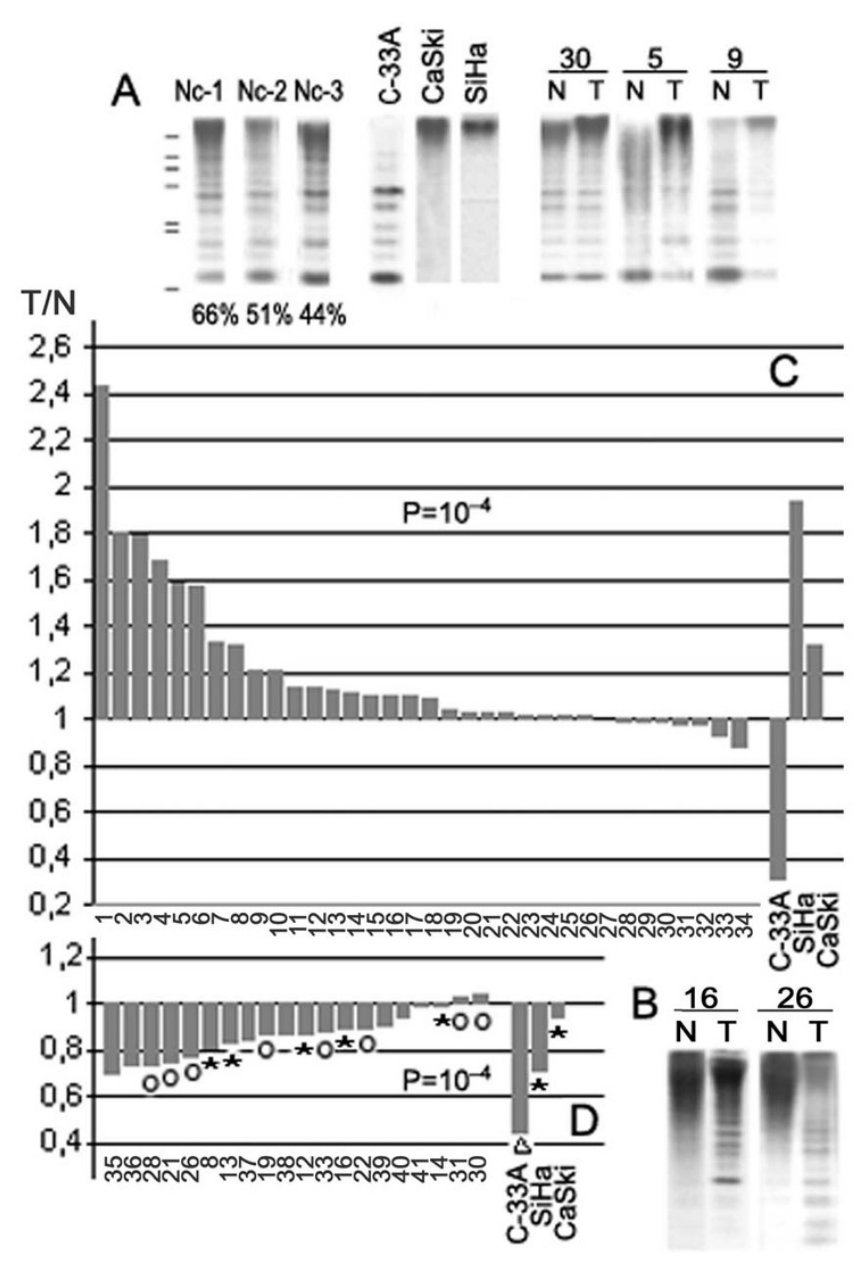

Figure 3

Analisis of methylation status of 3.3-kb and Sat2 repeats in HPV-positive cervical tumors by Southern blot hybridization. Nc, normal cervix from non-cervicalcancer patients; $\mathrm{T}$, tumor; $\mathrm{N}$, tumor-adjacent normal tissue. Lines to the left of the panel are molecular mass markers (from top to bottom, 24.3, 9.4, 6.6, 4.4, 2.3, 2.0, and $0.5 \mathrm{~kb}$ ). (A) Hybridization with the 3.3-kb repeat-specific probe, Nael digests of DNAs. Numbers under the panels indicate the percentage of the high-molecular-weight hybridization signal $(>4.4 \mathrm{~kb})$ to the total hybridization signal for each track. (B) Hybridization with the Sat2-specfic oligonucleotide, BstBI digests of DNAs. (C) Hypermethylation of 3.3-kb repeats in tumors. (D) Hypomethylation of Sat2 in tumors. The asterisk and triangle indicate samples with hypermethylation and hypomethylation of 3.3-kb repeats, respectively; the circle unchanged methylation status of $3.3-\mathrm{kb}$ repeats.

\section{Both hypermethylation of 3.3-kb repeats and hypomethylation of satellite repeat Sat2 in cervical tumors and cancer cell lines}

The high frequency of hypermethylation of 3.3-kb repeats in cervical cancer has not been reported earlier. In order to determine whether 3.3-kb repeat hypermethylation takes place in HPV-positive cervical tumors along with the wellknown hypomethylation of different repeats in tumors, the methylation status of Sat 2 was analyzed by Southern blot hybridization (Figure 3B and 3D). The Sat 2 methylation status in normal and tumor cervical tissues was not known. Here, no low-molecular-weight fragments $(<4.4$ $\mathrm{kb})$ were revealed by Southern blot analysis in normal cervical tissues adjacent to tumors. This indicates that Sat2 is highly methylated in normal cervix just as in other human normal tissues. On the contrary, a large portion of the hybridization signal was observed in the low-molecularweight fragments $(<4.4 \mathrm{~kb})$ in tumors demonstrating hypomethylation of Sat2. Sat 2 hypomethylation was revealed in 15 out of $20(75 \%)$ tumors relative to normal adjacent tissues and in 5 cancer cell lines examined (Figure 3D; $\left.\mathrm{P}=10^{-4}\right)$. Hypermethylation of 3.3-kb repeats and hypomethylation of Sat 2 can coexist in the same tumor (Figure 3D and Additional file 1). On the other hand, Sat2 hypomethylation was observed in the tumors in the absence of 3.3-kb repeat hypermethylation indicating that the changes in the methylation pattern of different repeats are independent.

\section{Expression of DUX genes by RT-PCR}

The distribution of some DUX-related transcripts in normal and tumor cervical tissues was analyzed by RT-PCR with DUX4-specific primers. The products of RT-PCR of predicted size were revealed in normal uterine cervix and in normal tissues adjacent to cervical tumors. (Figure 4, Table 1). The expression levels in normal tissues were low compared to that of a control gene, GAPDH. To reveal the transcription suppression in tumors compared to normal tissues, RT-PCR products were analyzed by Southern blot hybridization with [ $\left.{ }^{32} \mathrm{P}\right]$-labeled DUX4-specific oligonucleotide. In 30 out of 44 (68.2\%) cervical carcinomas the [32P] RT-PCR bands were undetectable or faint compared to normal tissues. Twenty four tumors had matched normal tissues and 20 tumors were compared to the average from 5 healthy cervical tissue samples. The PCR products were absent in 5 out of 24 (20.8\%) normal tissues adjacent to cervical tumors with suppression of DUX transcription. This indicates that interruption of DUX transcription may be an early event in carcinogenesis. The PCR products were also absent in $4 \mathrm{HPV}$-positive cancer cell lines.

The specificity of PCR amplification was tested by cloning the 299-bp RT-PCR products of C-33A cell lines and sequencing of 11 such clones. All copies were highly homologous to DUX4, DUX4c (100-94\%), and DUX10 (99.7-89\%). The cloned sequences were less similar to DUX1-3 and DUX5 (84-90\%). One third of the transcripts had perfect ORFs. Thus, the transcripts revealed by RT-PCR in cervical cells are highly homologous to DUX family genes. 

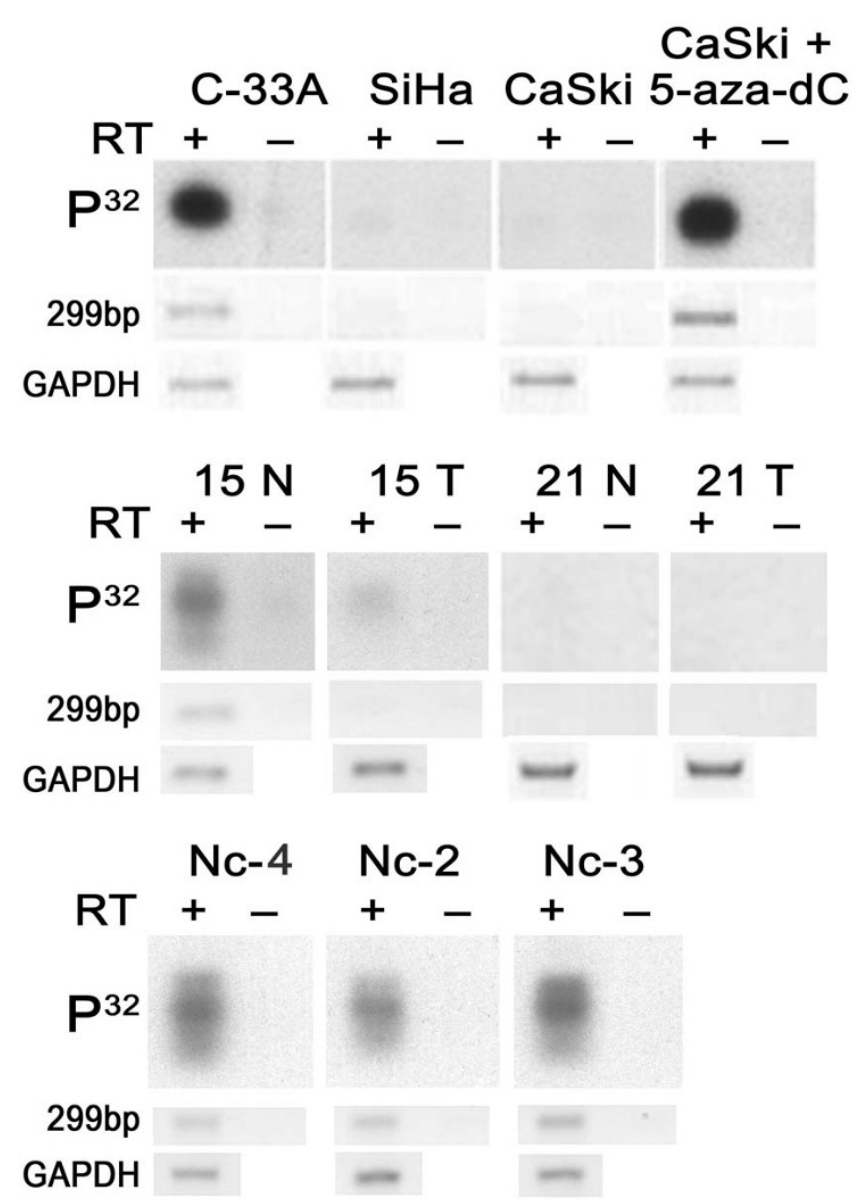

\section{Figure 4}

Analysis of DUX gene expression in cervical tumors and cell lines by RT-PCR. Top row: Southern blot hybridization of PCR products with the DUX4-specific [32] Plabeled oligonucleotide. Middle and bottom rows, electrophoregrams after ethidium bromide staining. GAPDH, a control for RNA stability and concentration. RT, reverse transcriptase; Nc, normal cervix from non-cervical-cancer patients; T, tumor; N, tumor-adjacent normal tissue. Patient numbers are as in figure 3.

\section{Comparison of 3.3-kb repeat methylation status with DUX gene expression}

The results of both 3.3-kb repeat methylation status and DUX gene expression were available for 24 carcinomas and matched normal tissue (Table 2). DUX mRNA expression was suppressed in 10 carcinomas with hypermethylation. Four highly methylated cell lines had no DUX transcripts. The transcripts were revealed in only one cancer cell line with hypomethylated 3.3-kb repeats (C-33A). Thus, there is a significant correlation between hypermethylation of $3.3-\mathrm{kb}$ repeats and down-regulation of $D U X$ transcription. This indicates that methylation plays a role in inactivation of DUX transcription. However, there were 8 out of $18(44 \%)$ tumors that had lost DUX transcripts without change in methylation status compared to nonmalignant tissues. These findings suggest that there are other mechanisms besides DNA methylation underlying the suppression of DUX expression.

\section{Re-expression of DUX genes after treatment with 5-aza- $d C$}

Re-expression of DUX genes after 5-aza-dC treatment was revealed in one out of four highly methylated cervical cell lines, CaSki, which confirms both the role of methylation in the expression control of DUX genes and the existence of other mechanisms of DUX gene silencing (Figure 4).

\section{Discussion}

Prevalence of hypermethylation over hypomethylation of 3.3-kb repeats in HPV-positive tumors

Demethylation at repeated DNA sequences is a common hallmark of human cancers and can be used as a surrogate marker of genome-wide methylation changes. [1-3]. We have demonstrated that the 3.3 -kb repetitive elements are heavily but not completely methylated in normal cervical tissues and subject to hypermethylation in more than $50 \%$ of HPV-positive cervical tumors and four cervical cancer cell lines. It has been shown that $3.3-\mathrm{kb}$ repeats are hypomethylated in glioblastomas and leukemia cell lines; they are hypomethylated in some portion of ovarian and Wilms tumors but hypermethylated in another portion of these tumors [23-25]. We observed strong hypomethylation of $3.3-\mathrm{kb}$ repeats relative to normal cervical epithelium only in HPV-negative cancer cell line and have concluded that 3.3-kb repeat hypermethylation is the predominant event in cervical cancer. There were no HPVnegative cervical tumors among our samples, and the methylation status of $3.3-\mathrm{kb}$ repeats in them remains to be evaluated, but one cannot exclude that the prevalence of the $3.3-\mathrm{kb}$ repeat hypermethylation in cervical tumors is related to HPV genome persistence. HR-HPVs induce carcinomas by expressing viral oncogenes E6 and E7 [4]. E7 deregulates several cellular pathways. In particular, it inactivates the retinoblastoma tumor suppressor protein (Rb) [29]. In normal cells, Rb regulates DNA methyltransferase 1 (DNMT1) that maintains DNA methylation during $S$ phase of the cell cycle by at least two mechanisms. $\mathrm{Rb}$ directly interacts with and modulates DNMT1 activity, and $\mathrm{Rb}$ is required for proper cell cycle regulation of Dnmt-1 transcription [30,31]. Oncogene E7 disrupts this regulation, abolishing $\mathrm{Rb}$; in addition, it directly interacts with and activates DNMT1 [32]. It has been shown recently that DNMT1 is necessary to maintain the $3.3-\mathrm{kb}$ repeat methylation [33]. The fine mechanisms responsible for changes of 3.3-kb repeat methylation status remain to be clarified, but the persistence of E7 in HPV-positive tumors likely ensures prevalence of hypermethylation over hypomethylation of $3.3-\mathrm{kb}$ repeats in contrast to 
Table I: Frequency of down-regulation of expression of DUX-related genes in normal tissues and cervical carcinomas

\begin{tabular}{lcc}
\hline Samples & No. tested & Down-regulation of mRNA \\
\hline Normal cervical tissues & 5 & 0 \\
\hline Adjacent to tumors nonmalignant cervical tissues & 24 & $5(20.8 \%)^{*}$ \\
Tumors & 44 & $30(68.2 \%)$ \\
& & $0.003^{* *}$ \\
Cervical cancer cell lines & 5 & 4
\end{tabular}

Down-regulation was defined as the ratio normal/tumor exhibiting at least threefold reduction of mRNA level in tumor or the absence of mRNA expression.

* Products of PCR were absent in adjacent normal tissue as well as matched tumor.

*** Fisher's exact test

virus-negative tumors where hypomethylation or both processes may take place. Other tandem repeats, NBL2, have been found to be hypomethylated in some types of cancer but hypermethylated in others [34,35]. Taken together, these data bring up the question of tumor-type specificity in epigenetic changes of repeats.

\section{Sequence-specific 3.3-kb repeat methylation}

We have demonstrated that different regions of the $3.3-\mathrm{kb}$ monomer were irregularly methylated in normal tissues and were subject to hypermethylation independently from one another in the same tumor. The 5 ' region (Sc-1) was less methylated in normal tissues but more susceptible to both hypomethylation and hypermethylation in tumor cells than other regions. Recently, the presence of a hypermethylation-resistant region within the 3.3-kb monomer was shown in ovarian and Wilms tumors [25]. This hypermethylation-resistant region is located only 70 and 100 nucleotides upstream from our Sq-2 region and the TATA box, respectively. The Sq-2 region is noticeably methylated in normal tissues, and its methylation level showed no significant changes in tumors. Overall, at least three subregions with different status and susceptibility to hypermethylation have been found within the 5 ' half of the 3.3-kb monomer [25] and the Sq1 and Sq2 regions. Both hypomethylation and hypermethylation of different CpG dinucleotides was shown in a short region of NBL2, a tandem DNA repeat, in tumors [36].

Table 2: Correlation between 3.3-kb repeats hypermethylation and loss of expression of DUX mRNA in cervical carcinomas and cancer cell lines

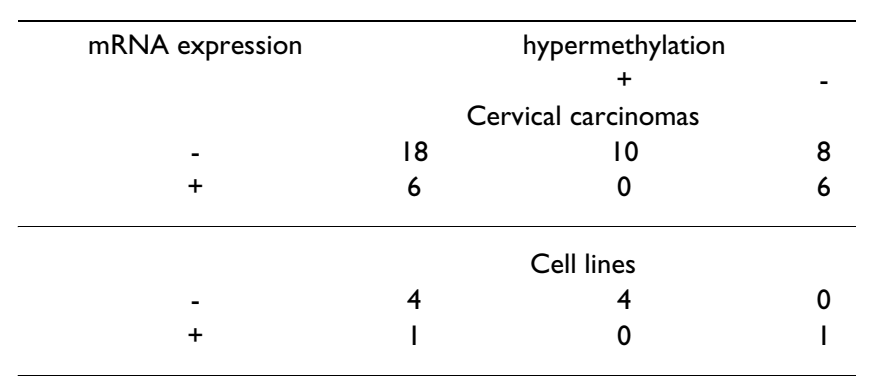

Hence, these studies and our data demonstrate that changes in the methylation status of genomic repeats in tumors may be sequence-specific. This indicates that the choice of the region to test may greatly influence conclusions reached by studying the methylation status of DNA repeats in cancer.

Different local susceptibility to methylation can be due to the complex structure of the 3.3-kb monomer, which includes several known sequence motifs: double homeobox, LSau, and hhspm3 [8,37]. Several regulator sequences have been found within these motifs. The $5^{\prime}$ region of the 3.3-kb element studied here (Sq-1) is about $200 \mathrm{bp}$ downstream from the LSau motif (Figure 1). LSau contains an exceptionally strong transcriptional enhancer [38]. Our middle region of the 3.3-kb element (Sq-2) includes a fragment of hhspm3. This region can function as a promoter in reporter assays and includes a TATA box and a transcription initiation site of DUX4 $[12,16]$. It has been shown that the multiprotein complex containing the transcription activator/repressor YY1 binds this region in HeLa cells and represses transcription of genes located upstream from D4Z4 [39]. The 3' end of the 3.3-kb element was shown to have a strong activator in a reporter assay [40]. Our hypermethylation-susceptible Sq-3 region lies within this fragment. It is possible that the interplay between the system of DNA methylation and regulatory factors binding these different regions determines their methylation levels in normal tissues and their susceptibility to hypermethylation in tumors. It is also possible that tissue-specific regulatory factors determine tumor-type specificity in epigenetic changes of 3.3-kb repeats discussed above.

\section{Both Sat2 hypomethylation and 3.3-kb repeat hypermethylation in tumors}

We observed hypomethylation of Sat2 in cervical tumors along with hypermethylation of 3.3-kb repeats. It has been shown that Sat2 hypomethylation is significantly associated with global DNA hypomethylation in different tumors [2,3]. Thus, hypermethylation of $3.3-\mathrm{kb}$ repeats does not interfere with the process of DNA hypomethyla- 
tion in tumors. The mechanisms underlying these opposite processes are not known. Both Sat 2 and 3.3-kb repeats are targets of DNMT3b, but only the latter is a target of DNMT1 [28,33,41], which can explain the different changes in their methylation status, in particular, in tumors. In addition, different epigenetic fates of two repeat types in the same tumor can be predetermined by their chromatin structure in normal cells: Sat2 DNA sequences reside in the centromere-adjacent heterochromatin, while $3.3-\mathrm{kb}$ repeats within the D4Z4 array exhibit unexpressed euchromatin-like features [2,42].

Hypomethylation of Sat 2 was revealed in tumors with and without hypermethylation of $3.3-\mathrm{kb}$ repeats. The absence of associations between changes of methylation status of two types of DNA repeats confirms the independent role of DNA hypo- and hypermethylation in tumor formation or progression.

\section{Down-regulation of transcription of DUX-related genes in tumors}

Transcriptional repression of DUX genes occurred in $68 \%$ of cervical carcinomas by methylation and some other mechanism. Proof of transcription of DUX genes in some normal cells has been provided [14,17]. We demonstrated that most normal cervical tissues showed clearly detectable, albeit low, levels of transcription from 3.3-kb repeat ORFs. Sequence analysis has demonstrated high homology of the transcripts amplified using our primers to DUX4, DUX4c, and DUX10 genes (89-100\%), but not all transcripts have perfect ORFs. Our findings are consistent with previous studies that indicate that, in spite of hundreds of 3.3-kb copies in the human genome, there are not so many transcripts that could be translated into functional DUX proteins $[9,15,17]$. Despite many investigations, it is still unclear whether DUX proteins are expressed in normal tissues. Currently, the evidence for the presence of a protein in vivo has only been obtained for DUX4 and DUX1 genes. Both proteins are expressed in human-derived rhabdomyosarcoma cell lines, and DUX4 is expressed in myoblasts of FSHD patients [14-16]. No evidence for the presence of DUX proteins in normal cells has yet been obtained. Surprisingly, the DUX4 ORF was recently shown to be conserved over 100 million years of evolution [43]. The authors believe that the DUX4 ORF conservation was not occasional but was selected, most likely, for the proteincoding function. High frequency of DUX4 transcriptional down-regulation in cervical tumors is an additional indirect evidence for the putative protein-coding function of 3.3-kb repeats and an argument for further search for DUX proteins in normal somatic and embryonic tissues.

\section{A possible role of hypermethylation and transcriptional silencing of 3.3-kb repeats in cervical cancer}

What is the role of hypermethylation and transcriptional silencing of the 3.3-kb repeats in carcinogenesis consider- ing low quantities of functional DUX proteins in normal cells? Some biological functions of DUX proteins are now known. The direct transcriptional target of the DUX4 protein has been identified. DUX 4 interacts in vitro with a ciselement in the promoter region of paired-like homeodomain transcription factor 1 (PITX1) and activates expression of the endogenous PITX1 gene in myoblasts [16]. In turn, PITX1 is a positive regulator of p53 and negative regulator of the RAS pathway $[44,45]$. In addition, DUX4 is a proapoptotic protein, and its forced exogenous expression in cell culture leads to cell death via apoptosis [15]. It is likely that DUX4 might be an initial trigger of a cascade of transcription factors regulating protooncogenes, tumor suppressors, and proapoptotic genes. Low expression of an initial transcription factor frequently occurs in embryonic differentiation. Thus, extremely low concentration of DUX4 in normal cells is not surprising taking into consideration its biological functions, and DUX4 silencing in tumors might deregulate several pathways usually affected in them.

An alternative view is that $3.3-\mathrm{kb}$ repeats have a non-coding, regulatory function and play a role in the formation and maintenance of heterochromatin in the subtelomeric regions of chromosomes 4 and 10 or in the maintenance of higher-order chromatin structure and regulation of neighboring gene expression on the chromosomes in normal cells $[38,39,46-48]$. It was shown that the structure of $3.3-\mathrm{kb}$ repeat chromatin in both $4 \mathrm{q}$ and $10 \mathrm{q}$ is similar to that of unexpressed euchromatin rather than of constitutive heterochromatin $[25,42]$. It remains to be established whether the overall increase in the $3.3-\mathrm{kb}$ repeat methylation level in tumors can have an influence on the heterochromatinization of $3.3-\mathrm{kb}$ repeats and/or changes of higher-order chromatin structure and expression of neighboring genes.

\section{Conclusion}

Our results demonstrate that hypermethylation rather than hypomethylation of $3.3-\mathrm{kb}$ repeats is a frequent event in HPV-associated cervical cancer and show a more complex pattern of changes in genome methylation in cancer than previously thought.

\section{Competing interests}

The authors declare that they have no competing interests.

\section{Authors' contributions}

AK carried out the analysis of repeat methylation status, statistical analysis, and contributed to the draft of the manuscript. LP carried out the RNA and DNA extraction and RT-PCR analysis. FL conceived the study and critically revised the manuscript. NK contributed to study concept and design and prepared the draft of the manuscript. All authors have read and approved the final version of the manuscript. 


\section{Additional material}

\section{Additional file 1}

Supplementary Table. Hypermethylation of 3.3-kb repeats and hypomethylation of Sat 2 repeats in cervical tumors. Correlation between hypermethylation of 3.3-kb repeats and hypomethylation of satellite repeats Sat 2 are shown in tumor samples.

Click here for file

[http://www.biomedcentral.com/content/supplementary/17558794-2-30-S1.pdf]

\section{Acknowledgements}

The study was supported by grants from the ISTC (\#33|2) and the Russian Foundation of Basic Science (\# 07-04-007-08)

\section{References}

I. Kisseljova NP, Kisseljov FL: DNA demethylation and carcinogenesis. Biochemistry (Mosc) 2005, 70:743-752.

2. Ehrlich M: DNA methylation in cancer: too much, but also too little. Oncogene 2002, $21: 5400-5413$.

3. Wilson AS, Power BE, Molloy PL: DNA hypomethylation and human diseases. Biochim Biophys Acta 2007, 1775:138-162.

4. zur Hausen $\mathrm{H}$ : Papillomaviruses and cancer: from basic studies to clinical application. Nat Rev Cancer 2002, 2:342-350.

5. Kim YI, Giuliano A, Hatch KD, Schneider A, Nour MA, Dallal GE, Selhub J, Mason JB: Global DNA hypomethylation increases progressively in cervical dysplasia and carcinoma. Cancer 1994 74:893-899.

6. Shuangshoti S, Hourpai N, Pumsuk U, Mutirangura A: Line-I hypomethylation in multistage carcinogenesis of the uterine cervix. Asian Pac J Cancer Prev 2007, 8:307-309.

7. Gonzalgo ML, Liang G, Spruck CH 3rd, Zingg JM, Rideout WM 3rd, Jones PA: Identification and characterization of differentially methylated regions of genomic DNA by methylation-sensitive arbitrarily primed PCR. Cancer Res 1997, 57:594-599.

8. Hewitt JE, Lyle R, Clark LN, Valleley EM, Wright TJ, Wijmenga C, van Deutekom JC, Francis F, Sharpe PT, Hofker M, et al.: Analysis of the tandem repeat locus D4Z4 associated with facioscapulohumeral muscular dystrophy. Hum Mol Genet 1994, 3:1287-1295.

9. Lyle R, Wright TJ, Clark LN, Hewitt JE: The FSHD-associated repeat, D4Z4, is a member of a dispersed family of homeobox-containing repeats, subsets of which are clustered on the short arms of the acrocentric chromosomes. Genomics 1995, 28:389-397.

10. van Geel M, Dickson MC, Beck AF, Bolland DJ, Frants RR, Maarel SM van der, de Jong PJ, Hewitt JE: Genomic analysis of human chromosome $10 \mathrm{q}$ and $4 \mathrm{q}$ telomeres suggests a common origin. Genomics 2002, 79:210-217.

II. Cacurri S, Piazzo N, Deidda G, Vigneti E, Galluzzi G, Colantoni L, Merico B, Ricci E, Felicetti L: Sequence homology between 4qter and IOqter loci facilitates the instability of subtelomeric Kpnl repeat units implicated in facioscapulohumeral muscular dystrophy. Am J Hum Genet 1998, 63: I8I-190.

12. Gabriels J, Beckers MC, Ding H, De Vriese A, Plaisance S, Maarel SM van der, Padberg GW, Frants RR, Hewitt JE, Collen D, et al.: Nucleotide sequence of the partially deleted D4Z4 locus in a patient with FSHD identifies a putative gene within each 3.3 kb element. Gene 1999, 236:25-32

13. Upadhyaya M, Cooper DN: FSHD facioscapulohumeral muscular dystrophy: clinical medicine and molecular cell biology. London; New York: BIOS Scientific Publishers; 2004

14. Ding H, Beckers MC, Plaisance S, Marynen P, Collen D, Belayew A Characterization of a double homeodomain protein (DUXI) encoded by a cDNA homologous to $3.3 \mathrm{~kb}$ dispersed repeated elements. Hum Mol Genet 1998, 7:168I-1694.

15. Kowaljow V, Marcowycz A, Ansseau E, Conde CB, Sauvage S, Matteotti C, Arias C, Corona ED, Nunez NG, Leo O, et al.: The DUX4 gene at the FSHDIA locus encodes a pro-apoptotic protein. Neuromuscul Disord 2007, 17:6 I I-623.

16. Dixit M, Ansseau E, Tassin A, Winokur S, Shi R, Qian H, Sauvage S, Matteotti C, van Acker AM, Leo O, et al.: DUX4, a candidate gene of facioscapulohumeral muscular dystrophy, encodes a transcriptional activator of PITXI. Proc Natl Acad Sci USA 2007, 104:|8|57-|8|62.

17. Beckers M, Gabriels J, Maarel S van der, De Vriese A, Frants RR, Collen $D$, Belayew A: Active genes in junk DNA? Characterization of DUX genes embedded within $3.3 \mathrm{~kb}$ repeated elements. Gene 200I, 264:5I-57.

18. Ansseau E, Laoudj-Chenvesse D, Marcowycz A, Sauvage S, Barro M, Tassin A, Matteotti C, van Acker A, Leroy A, Leclercq I, et al:: Characterization of the DUX4c gene located within a repeated element close to the FSHD locus. Neuromuscul Disord 2006:644-726.

19. Ostlund C, Garcia-Carrasquillo RM, Belayew A, Worman HJ: Intracellular trafficking and dynamics of double homeodomain proteins. Biochemistry 2005, 44:2378-2384.

20. Kondo T, Bobek MP, Kuick R, Lamb B, Zhu X, Narayan A, Bourc'his $D$, Viegas-Pequignot E, Ehrlich M, Hanash SM: Whole-genome methylation scan in ICF syndrome: hypomethylation of nonsatellite DNA repeats D4Z4 and NBL2. Hum Mol Genet 2000, 9:597-604.

21. Tsien F, Sun B, Hopkins NE, Vedanarayanan V, Figlewicz D, Winokur $S$, Ehrlich M: Methylation of the FSHD syndrome-linked subtelomeric repeat in normal and FSHD cell cultures and tissues. Mol Genet Metab 200I, 74:322-33I.

22. van Overveld PG, Lemmers RJ, Sandkuijl LA, Enthoven L, Winokur ST, Bakels F, Padberg GW, van Ommen G], Frants RR, Maarel SM van der: Hypomethylation of D4Z4 in 4q-linked and non-4qlinked facioscapulohumeral muscular dystrophy. Nat Genet 2003, 35:315-317.

23. Fraga MF, Ballestar E, Villar-Garea A, Boix-Chornet M, Espada J, Schotta G, Bonaldi T, Haydon C, Ropero S, Petrie K, et al.: Loss of acetylation at Lys 16 and trimethylation at Lys 20 of histone H4 is a common hallmark of human cancer. Nat Genet 2005, 37:391-400.

24. Cadieux B, Ching TT, VandenBerg SR, Costello JF: Genome-wide hypomethylation in human glioblastomas associated with specific copy number alteration, methylenetetrahydrofolate reductase allele status, and increased proliferation. Cancer Res 2006, 66:8469-8476.

25. Tsumagari K, Qi L, Jackson K, Shao C, Lacey M, Sowden J, Tawil R, Vedanarayanan V, Ehrlich M: Epigenetics of a tandem DNA repeat: chromatin DNasel sensitivity and opposite methylation changes in cancers. Nucleic Acids Res 2008, 36:2196-2207.

26. Ivanova TA, Golovina DA, Zavalishina LE, Volgareva GM, Katargin AN, Andreeva YY, Frank GA, Kisseljov FL, Kisseljova NP: Up-regulation of expression and lack of 5 ' CpG island hypermethylation of pl 6 INK4a in HPV-positive cervical carcinomas. BMC Cancer 2007, 7:47.

27. Samoylova EV, Shaikhaiev GO, Petrov SV, Kisseljova NP, Kisseljov FL: HPV infection in cervical-cancer cases in Russia. Int J Cancer 1995, 61:337-341.

28. Saito $Y$, Kanai $Y$, Sakamoto $M$, Saito $H$, Ishii $H$, Hirohashi S. Overexpression of a splice variant of DNA methyltransferase $3 \mathrm{~b}$, DNMT3b4, associated with DNA hypomethylation on pericentromeric satellite regions during human hepatocarcinogenesis. Proc Natl Acad Sci USA 2002, 99:10060-10065.

29. Dyson N, Howley PM, Munger K, Harlow E: The human papilloma virus- $16 \mathrm{E7}$ oncoprotein is able to bind to the retinoblastoma gene product. Science 1989, 243:934-937.

30. Pradhan S, Kim GD: The retinoblastoma gene product interacts with maintenance human DNA (cytosine-5) methyltransferase and modulates its activity. Embo J 2002, 21:779-788.

31. McCabe MT, Davis JN, Day ML: Regulation of DNA methyltransferase I by the pRb/E2FI pathway. Cancer Res 2005, 65:3624-3632.

32. Burgers WA, Blanchon L, Pradhan S, de Launoit Y, Kouzarides T, Fuks F: Viral oncoproteins target the DNA methyltransferases. Oncogene 2007, 26:1650-1655.

33. Egger G, Jeong S, Escobar SG, Cortez CC, Li TW, Saito Y, Yoo CB, Jones PA, Liang G: Identification of DNMTI (DNA methyltransferase I) hypomorphs in somatic knockouts suggests an 
essential role for DNMTI in cell survival. Proc Natl Acad Sci USA 2006, I03: I 4080-I 4085.

34. Thoraval D, Asakawa J, Wimmer K, Kuick R, Lamb B, Richardson B, Ambros P, Glover T, Hanash S: Demethylation of repetitive DNA sequences in neuroblastoma. Genes Chromosomes Cancer 1996, 17:234-244.

35. Nishiyama R, Qi L, Tsumagari K, Weissbecker K, Dubeau L, Champagne $M$, Sikka $S$, Nagai $H$, Ehrlich M: A DNA repeat, NBL2, is hypermethylated in some cancers but hypomethylated in others. Cancer Biol Ther 2005, 4:440-448.

36. Nishiyama R, Qi L, Lacey M, Ehrlich M: Both hypomethylation and hypermethylation in a $\mathbf{0 . 2}$-kb region of a DNA repeat in cancer. Mol Cancer Res 2005, 3:617-626.

37. Winokur ST, Bengtsson U, Feddersen J, Mathews KD, Weiffenbach B, Bailey H, Markovich RP, Murray JC, Wasmuth JJ, Altherr MR, et al.: The DNA rearrangement associated with facioscapulohumeral muscular dystrophy involves a heterochromatinassociated repetitive element: implications for a role of chromatin structure in the pathogenesis of the disease. Chromosome Res 1994, 2:225-234.

38. Petrov A, Allinne J, Pirozhkova I, Laoudj D, Lipinski M, Vassetzky YS: A nuclear matrix attachment site in the $4 q 35$ locus has an enhancer-blocking activity in vivo: implications for the facioscapulo-humeral dystrophy. Genome Res 2008, 18:39-45.

39. Gabellini D, Green MR, Tupler R: Inappropriate gene activation in FSHD: a repressor complex binds a chromosomal repeat deleted in dystrophic muscle. Cell 2002, I 1 0:339-348.

40. Kawamura-Saito M, Yamazaki Y, Kaneko K, Kawaguchi N, Kanda H, Mukai H, Gotoh T, Motoi T, Fukayama M, Aburatani H, et al.: Fusion between CIC and DUX4 up-regulates PEA3 family genes in Ewing-like sarcomas with $t(4 ; 19)(q 35 ; q \mid 3)$ translocation. Hum Mol Genet 2006, I5:2 I25-2। 37 .

41. Weisenberger DJ, Velicescu M, Cheng JC, Gonzales FA, Liang G, Jones PA: Role of the DNA methyltransferase variant DNMT3b3 in DNA methylation. Mol Cancer Res 2004, 2:62-72.

42. Jiang $G$, Yang $F$, van Overveld $P G$, Vedanarayanan $V$, Maarel $S$ van der, Ehrlich $M$ : Testing the position-effect variegation hypothesis for facioscapulohumeral muscular dystrophy by analysis of histone modification and gene expression in subtelomeric 4q. Hum Mol Genet 2003, I 2:2909-292I.

43. Clapp J, Mitchell LM, Bolland DJ, Fantes J, Corcoran AE, Scotting PJ, Armour JA, Hewitt JE: Evolutionary conservation of a coding function for D4Z4, the tandem DNA repeat mutated in facioscapulohumeral muscular dystrophy. Am J Hum Genet 2007, 81:264-279.

44. Liu DX, Lobie PE: Transcriptional activation of $\mathrm{p} 53$ by Pitx I. Cell Death Differ 2007, 14:1893-1907.

45. Kolfschoten IG, van Leeuwen B, Berns K, Mullenders J, Beijersbergen RL, Bernards R, Voorhoeve PM, Agami R: A genetic screen identifies PITXI as a suppressor of RAS activity and tumorigenicity. Cell 2005, 121:849-858.

46. Tawil R, Maarel SM Van Der: Facioscapulohumeral muscular dystrophy. Muscle Nerve 2006, 34:I-I5.

47. Laoudj-Chenivesse D, Carnac G, Bisbal C, Hugon G, Bouillot S, Desnuelle C, Vassetzky Y, Fernandez A: Increased levels of adenine nucleotide translocator I protein and response to oxidative stress are early events in facioscapulohumeral muscular dystrophy muscle. J Mol Med 2005, 83:216-224.

48. Pirozhkova I, Petrov A, Dmitriev P, Laoudj D, Lipinski M, Vassetzky Y: A functional role for $4 \mathrm{qA} / \mathrm{B}$ in the structural rearrangement of the $4 q 35$ region and in the regulation of FRG I and ANTI in facioscapulohumeral dystrophy. PLOS ONE 2008, 3:e3389.

\section{Pre-publication history}

The pre-publication history for this paper can be accessed here:

http://www.biomedcentral.com/1755-8794/2/30/prepub
Publish with Bio Med Central and every scientist can read your work free of charge

"BioMed Central will be the most significant development for disseminating the results of biomedical research in our lifetime. "

Sir Paul Nurse, Cancer Research UK

Your research papers will be:

- available free of charge to the entire biomedical community

- peer reviewed and published immediately upon acceptance

- cited in PubMed and archived on PubMed Central

- yours - you keep the copyright
BioMedcentral 